\title{
Heart rate agreement between the 20- meter shuttle run test and virtual system in healthy children: a cross-sectional study
}

\author{
Cristiane A. Moran ${ }^{1 *}$, Simone Dal Corso ${ }^{2}$, Maria Teresa Bombig ${ }^{3}$, Andrey Jorge Serra ${ }^{3}$, Silvana Alves Pereira ${ }^{4}$ and
} Maria Stella Peccin ${ }^{3}$

\begin{abstract}
Background: Earlier studies evaluated the physiological responses to video games in children with different clinical conditions; however, no study has compared active video games with an incremental field test in healthy children. The purpose of this study was to verify the agreement between the 20-m shuttle run test (20 m-SRT) and virtual system (VS).

Methods: This is a cross-sectional study of 235 children ( $9.0 \pm 0.8$ years, 109 boys). The two tests were performed one week apart and the children were instructed not to engage in any physical exercise or sports in the $24 \mathrm{~h}$ preceding each test. Their resting heart rate was monitored for one minute and then throughout the tests. To evaluate the influence of motivation on the $20 \mathrm{~m} \mathrm{SRT}$ and (VS), at the end of the tests the children were asked to rate their motivation on a scale of zero to 10, zero being "not cool" and 10 "awesome". Perceived exertion at the end of the tests was assessed using the modified Borg scale.

Results: Maximum heart rate (HRmax) did not differ between the $20 \mathrm{~m}$-SRT and VS (194.4 \pm 10.2 bpm vs. $193.2 \pm$ 13.8 bpm, respectively). Both tests were similar for intensity $>$ and $<96 \%$ HRmax. The children showed greater exertion on the Borg scale and motivation during the VS. The multiple logistic regression model showed that motivation ( $p=0.98)$, sex $(p=0.53)$, age $(p=0.61)$, nutritional status $(p=0.65)$, and speed $(p=0.18)$ were not predictive factors of the child's reaching HRmax.
\end{abstract}

Conclusion: VS can be used as a tool to evaluate the intensity of maximal exercise tests, given that the percentage of children who achieved HRmax did not differ between the VS and $20 \mathrm{~m}$ SRT. The perceived exertion scales were correlated, but only the modified Borg scale correlated with HRmax in the $20 \mathrm{~m}$ SRT. The tests are motivational, and most children obtained the maximum VS score.

Keywords: Cardiology, Child, Exercise, Physical fitness, Virtual reality, Incremental stress test

\section{Background}

In recent years, interactive video games, known as Virtual System (VS) [1], have been used for rehabilitation in different areas, such as geriatrics [2], neurology [3-5] and pediatrics [6-8].

Earlier studies have evaluated the physiological responses to video games in healthy children or those with

\footnotetext{
* Correspondence: crismoran@uol.com.br

1Departamento de Ciências da Saúde, Federal University of Santa Catarina,

Campus Jardim das Avenidas, Rod. Gov. Jorge Lacerda, 3201, Araranguá,

Santa Catarina CEP 88.906-072, Brazil

Full list of author information is available at the end of the article
}

pulmonary disease $[8,9]$. In pediatrics, due to the motivational aspect $[10,11]$, researchers have used virtual systems as a resource to assess cardiac response. However, the findings of a recent systematic review demonstrate that the children in these studies did not reach maximum exercise intensity [12].

It is known that immediately before and at the onset of exercise, cardiovascular changes induced by the neural command center located in the bulbar region occur, resulting in increased heart rate and myocardial contractility [13].

(c) The Author(s). 2019 Open Access This article is distributed under the terms of the Creative Commons Attribution 4.0 International License (http://creativecommons.org/licenses/by/4.0/), which permits unrestricted use, distribution, and 
Heart rate $(\mathrm{HR})$, which represents intensity during exercise [14], is considered maximum above $180 \mathrm{bpm}$ in children, but the maximum threshold used is $200 \mathrm{bpm}$ $[15,16]$, while Pfeiffer considers a variation between 185 and $225 \mathrm{bpm} \mathrm{[17].}$

The latest systematic reviews $[12,18]$ of studies on children playing interactive video games have shown an association between an increase in exercise intensity from mild to moderate and a rise in HR. However, it is still unknown whether VS promotes vigorous intensity during a field test, such as the 20 -m shuttle run test (20 m-SRT).

The field test most widely used to assess aerobic capacity in healthy schoolchildren is called the $20 \mathrm{~m}$-SRT. Created in 1982 by Luc Léger et al., it was modified and validated in 1984 and is currently recommended for children and adolescents by several specialists in the area [19-22].

However, in the health area, researchers started to develop new interventions that use active video games $[18,23]$, indicating them in exercise tests as a health indicator in children and to assess cardiac capacity, using the $20 \mathrm{~m}$-SRT [24, 25].

The present study was based on the hypothesis that VS would offer a new approach to incremental testing in order to assess maximum heart rate (HRmax), considering possible equivalence between the tests. The aim of this study was to verify the agreement between $20 \mathrm{~m}$-SRT and VS.

\section{Methods}

\section{Study design and sample}

State elementary schools in the city of Sao Paulo, Brazil were randomly contacted to select healthy students aged 8 to 10 years, for this analytical cross-sectional study.

The ethics committee of the Federal University of São Paulo approved the study (protocol no. 1860/10. The parents gave written consent to take part in the research.

The sample size was calculated based on results obtained in an earlier pilot study conducted with six children that used HRmax as outcome variable. Thus, a sample of 235 children was obtained under the assumption that in the test comparing pairs of means (Student's t-test) for dependent samples, the standard deviation " $\sigma$ " for HRmax would be $21.16 \mathrm{bpm}$, with a difference in HRmax between the SRT and VS of $6.33 \mathrm{bpm}$. We considered a power of $90 \%$ and an error of $0.05 \%$.

\section{Protocol}

The city of Sao Paulo, Brazil is divided into five regions: east, west, north, south and center. We randomly contacted 5 schools, one from each of these regions, two of which declined to participate. A total of 312 children from the three remaining institutions were invited, 294 of whom completed the questionnaires on medical history and physical activity. Seventeen children were excluded for failing to attend on the day of medical screening, one child refused to be examined, and 34 required further investigations for exhibiting clinical and resting 12-lead electrocardiogram (ECG) changes. These children were referred to the outpatient clinic for congenital heart defects of the Federal University of Sao Paulo. Of the 242 eligible children, seven who did not appear for testing were considered losses and the remaining 235 were included in the final sample.

The parents completed a questionnaire on the child's clinical condition and any family history of heart disease. Next, a cardiologist assessed each child, recording their medical history and conducting a physical examination. Blood pressure was measured and a resting ECG was obtained, in order to rule out cardiovascular disease or clinical changes that could hinder physical activity.

\section{Evaluations}

Anthropometric data were used to characterize the sample and the variables were measured according to the Brazilian Pediatric Society's Orientation Manual (2009) [26].

\section{Body mass index}

Body mass index (BMI) was expressed as Z-score [27, 28] (Table 1). Body weight was measured with the child barefoot, wearing pants and a shirt. Digital scales (Glife $^{\oplus}$, Magna, China) were used, with a maximum load of $150 \mathrm{~kg}$ and resolution of $100 \mathrm{~g}$. Height was measured using a wall-mounted measuring tape, with the children barefoot, feet parallel and together, standing upright with their arms extended to the side and head positioned such that the lower part of the eye socket was at the same level as the earhole [26].

\section{Shuttle run test}

In the $20-\mathrm{m}$ shuttle run test, participants run $20 \mathrm{~m}$. The test starts at a standard speed of $8.0 \mathrm{~km} / \mathrm{h}$, increasing $0.5 \mathrm{~km} / \mathrm{h}$ every minute. Participants were advised of the test pace and a beeping sound signaled progression to the next level. The step rate was maintained by a standardized recorded beep played on a Toshiba TR8172MU CD player placed $10 \mathrm{~m}$ from the subject. The children were instructed to complete as many stages as possible. The test was ended when the child did not reach the expected distance, in line with the beep, and corresponding to the stage executed. The $20 \mathrm{~m}$-SRT was conducted on a flat surface at the multi-sport courts of the schools.

The 20-m course was marked with two cones and the children performed the tests individually to avoid their competing with other subjects. The raters accompanied all the tests as a safety measure and to encourage the children to complete the course within the time limits established for each stage. The children were verbally encouraged during each stage using standard phrases such as "you're doing really well" and "keep going" in a 
Table 1 Sample description

\begin{tabular}{|c|c|c|c|c|}
\hline Variable & & $\mathrm{N}$ & $(\%) /$ Mean/SD & $p$ value \\
\hline \multirow[t]{2}{*}{ Gender } & Female & 126 & 53.6 & 0.26 \\
\hline & Male & 109 & 46.4 & \\
\hline Age (years) & & & $9.0 / \pm 0.8$ & 0.01 \\
\hline \multirow[t]{2}{*}{ Anthropometry } & Weight (kg) & & $35.8 / \pm 9.9$ & 0.01 \\
\hline & Height (m) & & $1.4 / \pm 0.1$ & 0.20 \\
\hline \multirow[t]{4}{*}{ zBMI } & Low weight $(z$ score $<-2$ ) & 0 & & 0.50 \\
\hline & Normal $(-2 \leq$ z score $<+1)$ & 195 & 83 & \\
\hline & Overweight $(+1 \leq \mathrm{z}$ score $<+2)$ & 28 & 12 & \\
\hline & Obese $(z$ score $>+2)$ & 12 & 5 & \\
\hline
\end{tabular}

$\%=$ percentage; $\mathrm{kg}=$ kilograms; $\mathrm{m}=$ meters; $N=$ sample; $S D=$ standard deviation. $\mathrm{zBMI}$ : Body mass index (BMI) expressed as $\mathrm{Z}$ score

clear loud voice to guarantee total comprehension. The completed stages were converted into meters [21, 29].

\section{Virtual system}

The VS test was conducted in the school video rooms using the Nintendo Wii Free Run video game (Nintendo Company Ltd., Kyoto, Japan, model RVLSWC/RVLSWFSP), part of the Wii Fit Plus set of games. Free Run consists of producing a virtual running field. The Free Run game takes place on an island in the presence of virtual participants, known as avatars. The children run the race at a steady self-determined pace for $20 \mathrm{~min}$, with no obstacles or change in intensity.

A predefined path sets the distance in the game, and since an avatar that represents the player in the virtual environment provides the route, the distance in the real world has no relation to the one presented in the game. The player's movements are shown on three accelerometers in the Wii motion plus ${ }^{\circ}$ control. The static race provides body movements in the horizontal and vertical plane and the higher the exercise intensity, the greater the distance covered. To ensure reliable results, the researchers monitored the children throughout the test according to the manufacturer's instructions, guiding the placement of the controller near the body.

Test run time was determined in the VS for a maximum of twenty minutes, pre-established by the investigator for the free racing game. Distance was converted from miles to meters and speed was calculated based on time and distance.

Similarly to the $20 \mathrm{~m}$-SRT, the raters accompanied the tests to ensure the children completed the course until the end of the game and to provide verbal encouragement.

To eliminate any possible motivational influence from the VS, the order of the tests was randomized and the child was asked to choose an envelope, to determine which test (VS or $20 \mathrm{~m}$-SRT) would be performed first. The envelopes were opaque, sealed and numbered sequentially. The children performed the tests one week apart and were instructed not to engage in any physical exercise or sports in the $24 \mathrm{~h}$ preceding each test.

\section{Heart rate}

The children were monitored at rest for one minute and then throughout the tests. The variables used for statistical analysis were resting HR and HRmax. A Polar $\mathrm{RS} 800 \mathrm{CX}^{\circ}$ heart rate monitor was set up using Polar ProTrainer $5^{\oplus}$ software to collect 1 -s samples of heartbeats and R-R intervals, in line with the manufacturer's recommendations for maximum accuracy.

The HRmax data used were the values on the heart monitor display at the end of the exercise. Data stored on the heart monitor were transferred to the software at the end of the data collection sessions and the memory cleared to make room for further data collection.

Data recorded on Polar ProTrainer $5^{\circ}$ software served only for visual verification of the R-R curve. The chart indicated that heart rate increased during the tests and remained around HRmax at the end of the exercise. This initial check was used to ensure that a 1-s sample time was not affected by noise coming from the device.

Resting HR was assessed while the children were sitting in a comfortable position with their back and lower limbs supported for $60 \mathrm{~s}$, after a 5-min rest. HRmax, defined as the maximum value attained during the $20 \mathrm{~m}$-SRT and VS tests, was $200 \mathrm{bpm}$ [30]. HRmax was also expressed as percentage of the maximum predicted using the equation $\left(\frac{H R \max }{200}\right) * 100$, which showed a mean HR of 83 and $72 \%$ of predicted HRmax in the VS and $20 \mathrm{~m}$-SRT tests, respectively. The change in basal heart rate was also calculated, considering resting heart rate - HRmax achieved in the VS, expressed as a percentage:

$$
\begin{aligned}
& { }^{\Delta} \text { maximum HR achieved } \rightarrow \text { resting HR } \\
& \quad=\frac{(\text { maximum HR achieved-resting HR })}{\text { resting HR }} * 100
\end{aligned}
$$

Continuous heart rate monitoring was used to analyze maximum heart rate during the $20 \mathrm{~m}$-SRT and VS tests. 


\section{Motivation}

To evaluate the influence of motivation on the execution of the $20 \mathrm{~m}$-SRT and VS, the children were asked to rate their motivation at the end of the tests, on a scale of zero to 10, zero being "not cool" and 10 "awesome". Perceived exertion at the end of the tests was assessed using the modified Borg scale.

\section{Statistical analysis}

The Kolmogorov-Smirnov test was applied to determine how well heart rate (resting and maximum), the scale of perceived exertion, and motivation adhered to normal distribution. Descriptive statistics were expressed as means and standard deviations for the numerical variables, and as absolute and relative frequencies for their categorical counterparts. The chi-squared test was used to evaluate the intensity achieved in both tests. The paired Student's $t$ and Wilcoxon tests were applied to compare the $20 \mathrm{~m}$-SRT and VS for cardiac output and motivational factors, respectively. The independent Student's t-test was applied to compare the perceived exertion obtained with the $20 \mathrm{~m}$-SRT and VS. Multiple logistic regression was performed to analyze cardiac output by observing whether the child had reached HRmax ( $\geq 200 \mathrm{bpm}$ ), using sex, age, nutritional status, motivation and speed in the VS as predictors. Bland-Altman analysis was applied to examine the agreement between the two methods that measure the same parameter. It evaluated the difference in means (BIAS) between $20 \mathrm{~m}$-SRT and VS, to show the agreement between them. The Bland-Altman plot contains three lines: the center line being the difference in means, and the upper and lower lines the limits of agreement, which are calculated as $\pm 1.96 \times$ SD of the difference in means between both methods. The influence of starting the tests with the shuttle run or the VS was analyzed using the nonpaired Student's t-test. A 95\% confidence interval and significance level of $p<0.05$ were used for all analyses. Statistical information was obtained with SPSS statistical software, version 20.0 (SPSS, Chicago, IL, USA).

\section{Results}

A total of 235 children were included in the study, 118 and 117 of whom started on the VS and $20 \mathrm{~m}$-SRT, respectively. There was no difference in HRmax response $(p=0.056)$ between the order in which the tests were performed. The sample is characterized in Table 1.

In addition, we observed that both tests were similar for intensity $>$ and $<96 \%$ of predicted HRmax $(p=0.50)$, Table 2.

The children's performance between the $20 \mathrm{~m}$-SRT and VS tests showed no difference in HRmax $(p=0.18)$. The difference between the means is illustrated on a Bland-Altman plot (Fig. 1).

A comparison of the children's performance between the tests showed that there was no difference in HRmax
Table 2 Intensity $>96 \%$ of maximum HR reached on the tests

\begin{tabular}{llll}
\hline & & SV & \\
\hline \multirow{3}{*}{ SRT-20m } & & Yes & No \\
& Yes & 118 & 43 \\
& No & 36 & 38
\end{tabular}

SRT- $20 \mathrm{~m}=$ shuttle run teste de 20 metros; $S V=$ virtual system; $\%=$ percentagem

$(p=0.18)$. To assess HRmax agreement between VS and $20 \mathrm{~m}$-SRT, we plotted the differences against the mean for each subject using a Bland-Altman analysis. The mean difference was $0.1(p=0.18)$ (Fig. 1).

According to the results obtained, the number of children motivated in both tests was statistically significant $(p<0.001)$. However, most of the children $(84 \%)$ obtained the maximum score [10] in the VS.

All children reached HRmax in $10 \pm 5 \mathrm{~min}$. Exertion was greater on the Borg scale in the VS (7 points) compared to the $20 \mathrm{~m}$-SRT (6 points) $(p=0.002)$, and 30 $(12.8 \%)$ children were unable to complete the VS due to signs of exhaustion.

The multiple logistic regression model showed that motivation $(p=0.98)$, sex $(p=0.53)$, age $(p=0.61)$, nutritional status $(p=0.65)$, and speed $(p=0.18)$ were not predictive factors of the child's reaching HRmax $\geq 200 \mathrm{bpm}$.

The order of starting the tests, whether the $20 \mathrm{~m}$-SRT (117 children) or VS (118 children), showed no differences in maximum $(p=0.056)$ and mean HR $(p=0.208)$.

\section{Discussion}

A similar percentage of children reached HRmax in both tests. There was no difference in HRmax between tests, but mean HR was higher in the VS. The tests were similar in terms of intensity $>$ and $<96 \%$ of predicted HRmax. With respect to Borg scale scores, there was greater exertion in the VS when compared to the $20 \mathrm{~m}$-SRT, but the children were motivated in both tests.

The characteristics chosen for the VS, such as free running with no obstacles or change in intensity, allowed the children to dictate the pace of the exercise. This approach provided a level of intensity corresponding to $83 \%$ of estimated HRmax, a value similar to that recommended by the American College of Sports Medicine for prescribing training for children [9, 31].

High-intensity, constant-load exercise protocols are commonly used to assess children's tolerance to exercise [32]. Despite not being an incremental protocol, our findings demonstrate that the VS is an innovative exercise test, with a constant load profile, where heart response reaches maximum intensity. The children reached maximum HR after $10 \mathrm{~min}$, a time similar to that found in protocols using incremental tests, such as the Bruce protocol adapted for children [33, 34]. 


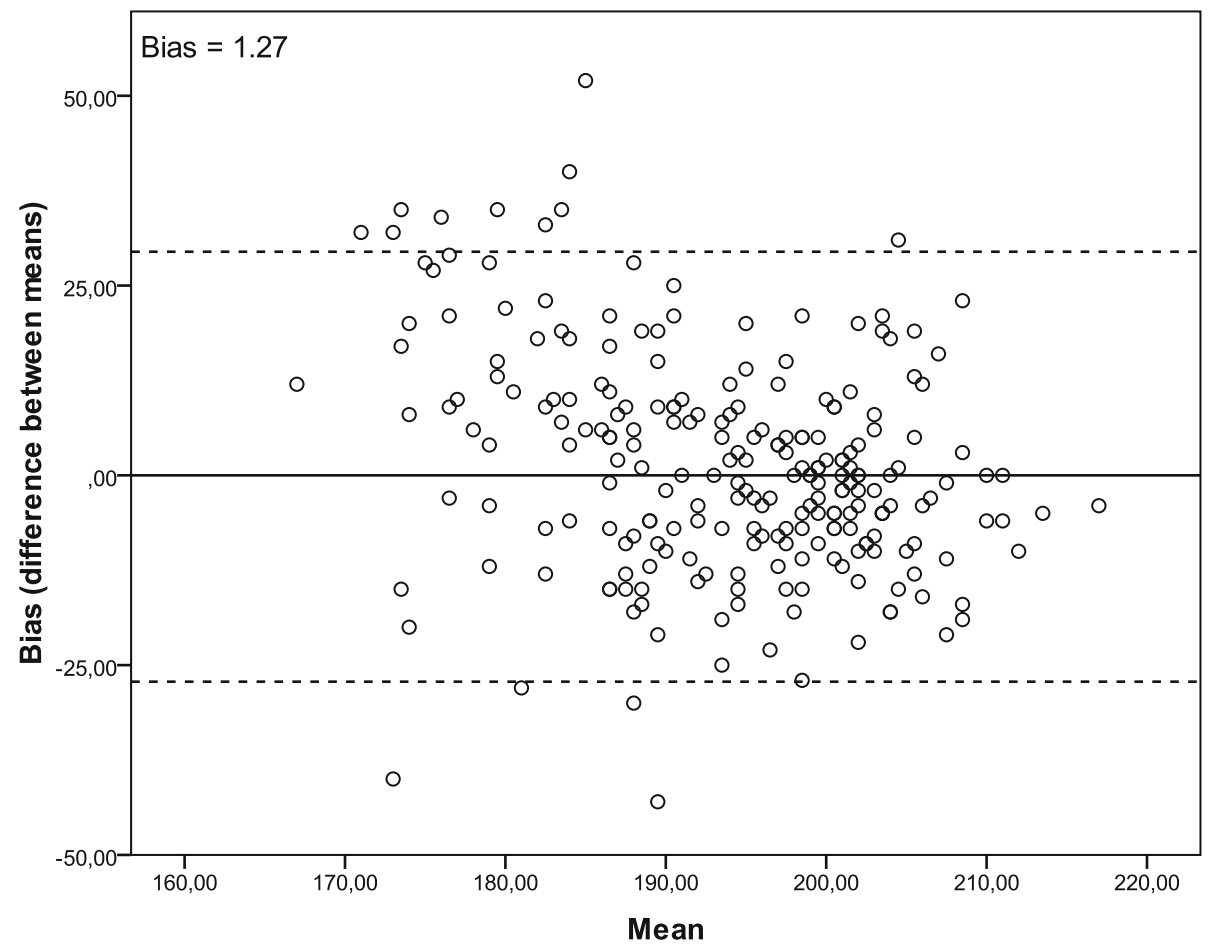

Fig. 1 Methodological agreement by Bland-Altman analysis for HRmax between VS and 20m-SRT. The y-axis (Bias) is the difference between heart rate means and the $x$-axis (Mean) is the individual mean for two tests. The bias was $0.1 \log (p=0.18)$

Physical effort acts directly on HR and is linearly related to exercise intensity $[35,36]$, exhibiting a strong correlation with maximal oxygen uptake $\left(\mathrm{VO}_{2} \max \right)$. As described in an earlier study, $\mathrm{VO}_{2}$ max is reached when maximum HR reaches $180 \mathrm{bpm}$ [37]. Although we did not take precise measures of maximum oxygen intake, the children may have reached $\mathrm{VO}_{2}$ max, since the maximum heart rate was above $200 \mathrm{bpm}$.

The increase in heart rate during exercise can be explained by the rise in sympathetic and decline in parasympathetic tone in healthy children [38, 39]. This expected response was observed in the VS, since we found a $120 \%$ increase from resting to maximum heart rate during the test, which was higher than that reported in studies with games that depend primarily on the lower limbs, whose values ranged from 51 to $98 \%$ [12].

Mean heart rate also contributes to a better understanding of the cardiovascular system's response. Straker found a mean $\mathrm{HR}$ of $130 \mathrm{bpm}$ in a video game, a value similar to that obtained in basketball and soccer [40]. In his study, children achieved a mean HR of $166 \mathrm{bpm}$ in the VS. Using this line of reasoning, we can prescribe video games as a physical activity.

Health promotion aims at a healthy lifestyle via aerobic training starting in childhood [41], and the basic concept when prescribing physical activity to children is to encourage regular exercise, prioritizing an entertaining environment [42].

The characteristics of the game selected for the VS, that is, free running without obstacles or with changes in intensity, is one of the strong points of the study, since the children themselves determined the pace of the exercise, thereby enabling $83 \%$ of estimated maximum $\mathrm{HR}$, a value above that recommended by the American College of Sports Medicine for prescribing physical activity in children $[9,31]$.

Studies recommend video games with an appropriate frequency and duration for physical training [10, 43, 44]. Thus, the device seems to contribute to physical activity, resulting in an appropriate exercise intensity for children [44], which contradicts Graves [31], demonstrating that video games were not enough to improve their cardiorespiratory fitness [31].

In adults, the perceived exertion scales show an association with signs of exhaustion and physiological measurements that include the musculoskeletal and cardiopulmonary systems. According to some researchers, applying perceived exertion scales in small children is difficult, because the rate of cognitive maturation depends on the age of the child and due to the fact that numerical interpretation of perceived exertion is not easily achieved [45-47]. 
The feeling of tiredness is considered a subjective response that can be influenced by several factors such as the clarity of instructions and the cognitive ability of the individual [48]. According to Prasad [49], the use of subjective assessments in children requires them to know the meaning of "out of breath" [49]. Homerding [48], believes that the modified Borg scale is adequate from the age of 9 years and suggests that the greater the child's functional impairment, the greater the respiratory discomfort and the easier the understanding of perceived exertion [48].

Children younger than 9 years old have difficulty interpreting perceived exertion scales $[48,50]$, which may be due to their phase of cognitive development. These findings were confirmed in the present study, since only maximum HR was correlated with the modified Borg scale in the $20 \mathrm{~m}$-SRT.

Studies demonstrate that the VS is a motivational instrument for physical activity and that children are motivated by a number of factors during a video game. These include the challenge of finishing the game, reaching objectives and their interest in the game, in addition to the sensory experience and their control over events [51-53].

Although there are no validated scales to assess children's motivation, the subjects of this study were demonstrably motivated by the tests. As such, new technologies, such as the interactive games of the VS, provide a motivational stimulus to children [54], a fact observed here, since most of the players scored higher in the VS compared to the shuttle run test.

The main study limitation was the children's difficulty in interpreting the perceived exertion scale, which can be explained by the age range selected. Although two schools refused to participate, restricting the sample to only three regions in the city of São Paulo, we obtained a representative sample.

The findings demonstrate that the VS can be implemented as an alternative assessment instrument for maximum exercise intensity for children in school settings and outpatient facilities, without the need for large spaces or substantial investment in equipment. Moreover, video games contribute to the motivational aspect of children because it is an entertaining and easy-to-understand instrument that can be used in rehabilitation programs, possibly leading to greater adherence of children to physical activities.

For future research, the authors suggest that studies be designed as clinical trials to rehabilitate children with cardiorespiratory and metabolic disorders in addition to the area of pediatric oncology. We also recommend studying physiological responses with an emphasis on the upper and lower limbs, according to the style of the game selected.

\section{Conclusions}

The VS can be used as a tool to evaluate the intensity of maximal exercise tests given that the percentage of children who achieved HRmax did not differ between the instrument and the $20 \mathrm{~m}$-SRT. The perceived exertion scales were correlated, but only the modified Borg scale correlated with HRmax in the $20 \mathrm{~m}$-SRT. The tests are motivational, and most children obtained the maximum score in the VS.

\section{Abbreviations \\ 20 m- SRT: 20-m shuttle run test; BMI: Body mass index; bpm: Beats per minute; HRmax: Maximum heart rate; $V_{2}$ max: Maximal oxygen uptake; VS: Virtual system \\ Acknowledgements \\ The graduate school from Federal University of Rio Grande do Norte and Coordenação de Aperfeiçoamento de Pessoal de Nível Superior - Brasil (CAPES) Finance Code 001 for the partial funding of the study.}

\section{Authors' contributions}

CAM SDC, MTB and AJS were responsible for study ideation and design of the work; SAP was responsible for statistical analysis; CAM wrote the initial version of the paper; SAP, MSP and CAM reviewed and contributed to the writing of the final version of the paper. CAM and MTB participated in the collection of data. All the authors read and approved the final version of the manuscript.

\section{Funding}

Not applicable.

\section{Availability of data and materials}

The dataset used and analyzed during the current study is available from the corresponding author on reasonable request.

Ethics approval and consent to participate

The ethics committee of the Federal University of São Paulo approved the study (protocol no. 1860/10. The parents gave written consent to take part in the research. The committee evaluated the ethical aspects of the study in accordance with The World Medical Association's Declaration of Helsinki. The study was explained in detail to the participants' parents. Parental written informed consent was obtained right before patient enrollment in all cases.

Consent for publication

Not applicable.

\section{Competing interests}

The authors declare that they have no competing interests.

\section{Author details}

${ }^{1}$ Departamento de Ciências da Saúde, Federal University of Santa Catarina, Campus Jardim das Avenidas, Rod. Gov. Jorge Lacerda, 3201, Araranguá, Santa Catarina CEP 88.906-072, Brazil. ${ }^{2}$ Nove de Julho University, São Paulo, Brazil. ${ }^{3}$ Federal University of São Paulo, São Paulo, SP, Brazil. ${ }^{4}$ Federal University of Rio Grande do Norte, Natal, Rio Grande do Norte, Brazil.

Received: 6 August 2019 Accepted: 28 November 2019

Published online: 12 December 2019

\section{References}

1. Epstein $L H$, Beecher MD, Graf $J$, Roemmich JN. Choice of interative dance and bicycle games in overweight and nonoverweight youth. Ann Behav Med. 2007;33(2):124-31.

2. Laver K, Ratcliffe J, George S, Burgess L, Crotty M. Is the Nintendo Wii fit really acceptable to older people? A discrete choice experiment. BMC Geriatr. 2011:11:64-71.

3. Mouawad MR, Doust CG, Max MD, McNulty PA. Wii -based movement the rap y to promote imp roved upper extremity function post -stroke: a pilot study. J Rehabil Med. 2011;43:527-33. 
4. Wikstrom EA. Validity and reliability of Nintendo Wii fit balance scores. J Athl Train. 2012;47(3):306-13.

5. Thomas S, Fazakarley L, Thomas PW, Brenton S, Collyer S, Perring S, et al. Testing the feasibility and acceptability of using the Nintendo Wii in the home to increase activity levels, vitality and well-being in people with multiple sclerosis (mii-vitalise): protocol for a pilot randomized controlled study. BMJ Open. 2014;4(5):e005172.

6. Warburton DER, Sarkany D, Johnson M, Rhodes RE, Whitford W, Esch BTA, Scott JM, Wong S, Bredin SSD. Metabolic requirements of interactive video game cycling. Med Sci Sports Exerc. 2009;41(4):920-6.

7. Mills A, Rosenberg M, Stratton G, Carter HH, Spence AL, Pugh CJA, et al. The effect of Exergaming on vascular function in children. J Pediatr. 2013;163:806-10.

8. Gomes ELFD, Carvalho CRF, Peixoto-Souza FS, Teixeira-Carvalho EF, Mendonça JFB, Stiburlov R, et al. Active video game exercise training improves the clinical control of asthma in children: randomized controlled trial. PLoS One. 2015;10(8).

9. Daley JA. Can exergaming contribute to improving physical activity levels and health outcomes in children? Pediatr. 2009;124(2):763-71

10. Graves LEF, Ridgers ND, Williams K, Stratton G, Atinkson G, Cable NT. The physiological cost and enjoyment of wii fit in adolescents, young adults, and older adults. J Phy Act Health. 2010;7:393-401.

11. Baranowski T, Abdelsamad D, Baranowski J, OConnor TM, Thompson D, Barnett A, Cerin E, Chen T. Impact of an active video game on healthy children's physical activity. Pediatr. 2012;129(3):e636-42.

12. Biddis $\mathrm{E}$, Irwin J. Active video games to promote physical activity in children and youth. Arch Pediatr Adolesc Med. 2010;164(7):664-72.

13. Mcardle WD, Katch Fl, Katch VL. Fisiologia do exercício: Energia, nutrição e desempenho humano. 4a. Edição. Guanaraba Koogan S.A. Rio de Janeiro. RJ: Editora; 1998.

14. Gao Z, Chen S, Pasco D, Pope Z. A meta-analysis of active video games on health outcomes among children and adolescents. Obes Rev. 2015; 16(9):783-94.

15. Silva OB, Saraiva $L C R$, Filho DCS. Teste ergométrico em crianças e adolescentes - maior tolerância ao esforço com o protocolo em rampa. Arq Bras Cardiol. 2007:89(6):391-7.

16. Davidson J, João PC, Rodrigues RO, Scavacini AS. Respostas cardiopulmonares durante o esforço em crianças e adolescentes nascidas prematuras. Rev Paul Pediatr. 2011;29(3):443-8.

17. Pfeiffer MET, Serra S. Teste de exercício cardiopulmonar em cardiopatas congênitos: visão do cardiopediatra. Rev DERC. 2012;18(4):114-7.

18. LeBlanc AG, Chaput J, McFarlane A, Colley RC, Thivel D, Biddle SJH, et al. Active videogames and health indicators in children and youth: a systematic review. PLoS One. 2013;8(6):e65351.

19. Mahoney C. 20-MST and PWC170 validity in non-Caucasian children in the UK. Br J Sp Med. 1992;26(1):45-8.

20. Montoro SB, Mendes RT, Arruda M, Zeferino AMB. Aptidão aeróbica de crianças e adolescentes obesos: procedimentos de controle. Rev Bras Ciênc da Saúde. 2009:VII(19):62-70.

21. Voss C, Sandercock G. Does the twenty meter shuttle-run test elicit maximal effort in 11-to-16- year-olds ? Pediatr Exerc Sci. 2009;21:55-62

22. Artero EG, España-Romero V, Castro-Piñero J, Ortega FB, Suni J, CastillGarzon MJ, et al. Reliability of field-based fitness tests in youth. Int J Sports Med. 2011;32:159-69.

23. Mellecker RR, Mc Manus AM. Active video games and physical activity recommendations: A comparison of the Gamercize Stepper, Xbox Kinect and Xavix J-Mat. J Sci Med Sport. xxx.2013 xxx-xxx.

24. Lang JJ, Belanger K, Poitras V, Janssen I, Tomkinson GR, Tremblay MS. Systematic review of the relationship between $20 \mathrm{~m}$ shuttle run performance and health indicators among children and youth. J Sci Med Sport. 2018;21:383-97.

25. Júnior M, de FJ, de Jíc, Neiva L. Predictive equations of maximum oxygen consumption by shuttle run test in children and adolescents: a systematic review. Rev Paul Pediatr. 2019:37(2):241-51.

26. Nutritional assessment of children and adolescents - Brazilian Pediatric Society's Orientation Manual (2009). Department of Nutrology. São Paulo: Brazilian Pediatric Society. Department of Nutrology, 2009.112 p.

27. Onis M, Onyango AW, Borghi E, Siyam A, Nishida C, Siekmann J. Development of a who growth reference for school-aged children and adolescents. Bull World Health Organ. 2007;85(9):660-7.
28. Abarca-Gómez $\mathrm{L}$, et al. Worldwide trends in body-mass index, underweight, overweight, and obesity from 1975 to 2016: a pooled analysis of 2416 population-based measurement studies in 128. 9 million children, adolescents, and adults. Lancet. 2017:390(10113): 2627-42.

29. Moran CA, Peccin MS, Bombig MT, Pereira AS, Dal CS. Performance and reproducibility on shuttle run test between obese and non-obese children: a cross-sectional study. BMC Pediatr. 2017;17:68.

30. Rowland, T W. Children's exercise physiology 2nd ed. Champaign, IL: Human Kinetics, 2005

31. Graves LEF, Ridgers ND, Stratton G. The contribution of upper limb and total body movement to adolescents' energy expenditure whilst playing Nintendo Wii. Eur J Appl Physiol. 2008;104(4):617-23.

32. Palange P, Ward SA, Carsel K-H, Casaburi R, Gallagher CG, Gosselink R, et al. Recommendations on the use of exercise testing in clinical practise. Eur Respir Jr. 2007;29:185-209.

33. Zijp MHMC, Ljsselstijn H, Takken T, Willemsen S, Tibboel D, Stan HJ, et al. Exercise testing of pre-school children using the Bruce treadmill protocol: new reference values. Eur J Appl Physiol. 2010;108:393-9.

34. Ghorayeb N, Costa RVC, Castro I, Daher DJ, Oliveira Filho JÁ, Oliveira MAB, et al. Diretriz em cardiologia do esporte e do exercício da Sociedade Brasileira de Cardiologia e da Sociedade Brasileira de Medicina do Esporte. Arq Bras Cardiol. 2013;100(1Supl.2):1-41.

35. Fletcher GF, Balady GJ, Amsterdam EA, Chaitman B, Eckel R, Fleg J, et al. Exercise standards for testing and training: a statement for healthcare professionals from the American Heart Association. Circ. 2001;104:1694-740.

36. Stephens P, Stephen MP. Exercise testing in children. Pediatr Clin N Am. 2004:1569-87.

37. Riopel DA, Taylor AB, Hohn AR. Blood pressure, heart rate, pressure rate product and electrocardiographic changes in healthy children during treadmill exercise. Am J Cardiol. 1979:44:697-705.

38. Goldberger JJ. Sympathovagal balance: how should we measure it ? Am J Physiol Heart Circ Physiol. 1999;276:H1273-80

39. Kannankeril PJ, Goldberger JJ. Parasympathetic effects on cardiac electrophysiology during exercise and recovery. Am J Physiol Heart Circ Physiol. 2002;282:H2091-8.

40. Straker L, Abbott R. Effect of screen-based media on energy expenditure and heart rate in 9-to 12-year-old children. Pediatr Exerc Sci. 2007;19:459-71.

41. Farinatti PTV, Monteiro WD. Fisiologia e avaliação funcional. Volume I, 4a edição. Editora Sprint. Rio de Janeiro. RJ. 2000.

42. Lazzoli JK, Nóbrega da ACL, Carvalho de T, Oliveira MAB, Teixeira JAC, Leitão MB, et al Atividade física e saúde na infância e adolescência. Rev Bras Med Esporte 1998; 4(4): 107-109.

43. Foley L, Maddison R. Use of active video games to increase physical activity in children: a (virtual) reality? Pediatr Exerc Sci. 2010;22:7-20.

44. Unnithan VB, Houser W, Fernhall B. Evaluation of the energy cost of playing a dance simulation video game in overweight and non-overweight children and adolescents. Int J Sports Med. 2006;27:804-9.

45. Borg GAV. Psychophysical bases of perceived exertion. Med Sci Sports Exerc. 1982;14(5):377-81

46. Burkhalter N. Evaluación de la escala borg de esfuerzo percibido aplicada a la rehabilitación cardíaca. Rev Latino-am.enfermagem. 1996; 4(3):65-73.

47. Yelling M, Lamb KL, Swaine IL. Validity of a pictorial perceived exertion scale for effort estimation and effort production during stepping exercise in adolescent children. Eur Phys Educ Rev. 2002;8:157-77.

48. Hommerding PX, Donadio MVF, Paim TF, Marostica PJC. The Borg scale is accurate in children and adolescents older than 9 years with cystic fibrosis. Respir Care. 2010;55(6):729-33.

49. Prasad SA, Randall SD, Balfour-Lynn IM. Fifteen-count breathlessness score: an objective measure for children. Pediatr Pulmonol. 2000;30: 56-62.

50. Oliveira JS, Campos TF, Borja RO, Silva ROE, Freitas DA, Oliveira LC, et al. Analysis of the rate of perceived exertion in the assessment of maximal respiratory pressures in children and adolescents. J Hum Growth Dev. 2012; 22(3):314-20.

51. Marijke JM, Paw CA, Jacobs WM, Vaessen EPG, Titze S, van Mechelen W. The motivation of children to play an active video game. J Sci Med Sport. 2008; 11:163-6. 
52. Staiano AE, Abraham AA, Calvert SL. Motivating effects of cooperative exergame play for overweight and obese adolescents. J Diab Sci Technol. 2012;6(4):812-20

53. Sun $\mathrm{H}$. Exergaming impact on physical activity and interest in elementary school children. Res Q Exerc Sport. 2012;83(2):212-20.

54. Levac D, Miller P, Missiuna C. Usual and virtual reality video game-based physiotherapy for children and youth with acquired brain injuries. Phys Occup Ther Pediatr. 2012;32(2):180-95.

\section{Publisher's Note}

Springer Nature remains neutral with regard to jurisdictional claims in published maps and institutional affiliations.

Ready to submit your research? Choose BMC and benefit from:

- fast, convenient online submission

- thorough peer review by experienced researchers in your field

- rapid publication on acceptance

- support for research data, including large and complex data types

- gold Open Access which fosters wider collaboration and increased citations

- maximum visibility for your research: over $100 \mathrm{M}$ website views per year

At BMC, research is always in progress.

Learn more biomedcentral.com/submissions 